\title{
El don de la palabra en el proceso de formación de un yatiri aymara
}

Manuel Chura es un especialista en ritual aymara, un yatiri, con más de veinticinco años de experiencia en la ciudad de La Paz (Bolivia). Yatiri, "el que sabe", es un especialista ceremonial diestro en las técnicas de predicción y consulta de hojas de coca. Conoce la etiología de las enfermedades "de la gente" y su tratamiento específico. Su formación exige un proceso selectivo vinculado con el golpe de que es objeto por parte del rayo, que le otorga su poder ${ }^{1}$. Existen otros procedimientos que reflejan la selección de que ha sido objeto el candidato a yatiri, como es el caso de los gemelos, los que nacen de pie (qalluni), los que superan con rapidez enfermedades supuestamente incurables, los sueños, las personas con defectos físicos relevantes (ciegos, cojos, mancos, etc.), así como los incontestablemente pobres. Todos ellos entran dentro de la categoría de supuestos elegidos o candidatos a ejercer el camino de los yatiri o "maestros", como se les conoce de forma coloquial. Por otra parte, estos factores de selección de los actuales "maestros" ceremoniales aymara coinciden con los criterios imperantes durante la Colonia ${ }^{2}$.

Manuel Chura ejerce su profesión leyendo la suerte y curando a sus clientes, con frecuencia "residentes" aymaras, que se acercan a su puesto habitual en las proximidades de la puerta principal de la iglesia de San Francisco. La "Suerte" de la coca muestra el valor fasto o nefasto de la consulta efectuada por el cliente. Cualquier conflicto o aflicción adopta

1 Harry TschopIK, Magia en Chucuito. Los aymaras del Perú (México: Instituto Indigenista Interamericano, 1968), p. 195; Xavier ALBO, "La experiencia religiosa aymara", Manuel M. MARZAL (coord.), Rostros indios de Dios (La Paz: CIPCA/HISBOL/UCB, 1992), p. 94.

2 Así se refleja en los textos de cronistas como Bernabé CoBo, "Historia del Nuevo Mundo" (1653), publicada en Obras del Padre Bernabé Cobo de la Compañia de Jesús (Madrid: Biblioteca de Autores Españoles, 1964), vol. II, pp. 214-215, y en las visitas efectuadas con motivo de los procesos de extirpación de idolatrías: Pablo J. DE ARRIAGA, "La extirpación de la idolatría en el Perú" (1621), Crónicas peruanas de interés indigena (Madrid: BAE, 1968). Sobre el rayo y la pertinencia de su poder en relación con los especialistas rituales andinos, A. M MARISCOTTI, "Los curi y el rayo", Actes du XLII Congrès International des Amèricanistes (Paris, 1978), 4, pp. 365-375. 
forma textual explícita, merced a los caracteres que el "maestro" es capaz de descifrar en la hoja de coca y en sus asociaciones con respecto al resto del conjunto ceremonial empleado en su lectura ${ }^{3}$.

Manuel es ciego, cualidad que acrecienta en gran manera su carisma como "maestro"; procede de una de las comunidades altiplánicas del Cantón de Ajllata Grande, Provincia de Omasuyo del Departamento de La Paz, en las cercanías del lago Titicaca. Las personas con malformaciones y carencias físicas son consideradas especialmente pertinentes en el ejercicio del campo ceremonial aymara. Los cuerpos maltrechos, torcidos e incompletos constituyen diferentes manifestaciones del poder de excisión del rayo; son "hijos del rayo" ${ }^{4}$. El propio cuerpo de los yatiri refleja el coste importante que implica encarnar el límite entre el dominio de lo sagrado y lo profano 5 .

El éxito de sus conocimientos como "maestro" ${ }^{6}$ le ha permitido alcanzar una prosperidad que no esconde en las usuales visitas a su comunidad durante el carnaval; participa igualmente en la celebración del núcleo escolar, a mediados de abril, y en la fiesta de Santa Rosa de Lima, patrona de la comunidad de Toque Ajllata, a finales de agosto. No escatima sus responsabilidades en el desempeño de "cargos" ", ni en relación con los gastos que le corresponden en los festejos comunitarios y en los

3 El estudio dirigido por Juan M. Ossio (coord.), "Cosmovisión andina y uso de la coca", La coca, tradición, rito, identidad (México: Inst. Indigenista Interamericano, 1989), pp. 231-381, muestra parte de los caracteres iconográficos atribuidos a la hoja en diferentes localizaciones andinas. Por su parte, William CARTER y Mauricio MAMANI, Coca en Bolivia (La Paz, 1986), pp. 384-434, presentan diversos rasgos conceptuales atribuidos a las hojas de coca en función de su apariencia, y gráficos representantivos de casos concretos de lectura ceremonial.

4 Así lo recoge Felipe GuAmán POMA, Nueva crónica y buen gobierno (1615), Crónicas de América, 29a, 29b, 29c (Madrid, 1987), p. 268.

5 Thérèse BOUYSSE-CASSAGNE y Olivia HARRIS, "Pacha: en torno al pensamiento aymaran, VV. AA., Tres reflexiones sobre el pensamiento andino (La Paz: HISBOL, 1987), p. 46.

6 Los especialistas rituales aymara reciben la denominación coloquial de "maestros", en referencia a su cualificada opinión y sabiduría en el campo ceremonial que les compete.

7 La vida comunitaria se estructura a partir de las responsabilidades compartidas mediante un sistema de "cargos", anuales y rotatorios, dependientes, tras el triunfo del Movimiento Nacionalista Revolucionario (MNR) en 1952, de los sindicatos agrícolas campesinos. Existen otros "cargos" de corte tradicional que desempeñan los "mandones", cuyos emblemas de poder son las varas que portan y el chicote cruzado sobre los hombros. Son personas de influencia en las costumbres, tradiciones y celebraciones colectivas. 
acuerdos de reciprocidad establecidos mediante ayni (sistema de intercambio de bienes y servicios, de carácter simétrico, extendido por todo el área andina). Su condición de "residente" sirve como nexo de unión y "puente" provisional para el acceso de familiares y conocidos al complicado entorno urbano de $\mathrm{La} \mathrm{Paz}^{8}$.

Manuel Chura es un "maestro" de reconocido prestigio entre sus clientes, a los que dedica en exclusiva su jornada laboral. Profesión y servicio son conceptos que se conjugan habitualmente entre los "maestros" ceremoniales aymara. La ciudad constituye un marco propicio para el negocio y el ejercicio de una profesión, mientras que el dominio rural facilita otro tipo de relación entre el "maestro" y su cliente, basada en el servicio. Manuel "lee" la hoja de coca con el tacto de sus dedos, pronosticando la "suerte" de sus pacientes en las variadas consultas de que es objeto. Reconoce también la etiología de las enfermedades que sufren las personas y aplica los tratamientos terapeúticos que considera más eficaces para resolver todo tipo de aflicciones.

Voy a presentar el resultado de una prolongada entrevista que sostuve con tata Manuchu en su casa de Río Seco - una de las numerosas villas populares que conforman la estructura mayoritaria de la ciudad de El Alto de La Paz- poco antes de concluir mi estancia en Bolivia durante el año 1991. El testimonio de Manuel Chura gira en torno a los conocimientos ceremoniales que un buen "maestro" debe poseer, su proceso de iniciación como yatiri y los requerimientos precisos para desempeñar su labor. Los diversos conceptos que afloran en su testimonio reflejan, entre otros aspectos, el papel prioritario otorgado a la conversación con los seres tutelares del altiplano, los que invisten de "poder" y autoridad al "maestro", y el uso eficaz de la palabra en el proceso de formación de un maestro ceremonial aymara.

M. CH.—Veinte años hasta ahora, yatiri, cincuenta años.

Pero ahora ¿cómo quieres saber? Ese quería preguntarte, entonces claro que usted sabes ino?"

G.F.—¿Su papá le enseñó antes?

M. CH.—Tenía mi 'maestro' siempre. 'Maestro' profesional. Claro que él me enseñaba y me llevaba a este... a otro lado, lugar se llama de Ojje al lado de Copacabana. También me ha llevado a este... a Jipi, Wayna Jipi, cerro de Wayna Jipi ${ }^{9}$. Después ya, tres veces Ojje, tres veces de

8 Los "residentes" urbanos facilitan el acceso gradual de familiares y paisanos a la ciudad.

9 El "maestro" tiene que visitar lugares de especial reconocimiento sagrado, investidos de poder. Así lo recoge Tomás HUANCA, El yatiri en la comunidad aymara 
Jipi ${ }^{10}$. Después iya!, poco a poco, poco a poco, poco a poco, iya! Después que me ha enseñado también jrecién me ha enseñado! No primera vez jasí no más me ha llevado! A otro lado, a otro lado... ¡No es fácil para ir a aprender! Algunos, claro que sí, bueno, algunos ya... directamente hacen; directamente preparan la mes $a^{11}$, sacan suerte ¿no? ¡Para un rato no más es! No es permanente. Claro que siempre, primer lugar tiene que ir; tiene que sacar una licencia, permiso ¿ya? que lo guarde ${ }^{12}$. Ahí tiene que contactar, tiene que conocer los otros lugares... se llama achachilas ¿no ve? Achachilas, si con eso tiene que ir a conocer pues. Después, recién con el sueño va a hablar con ellos. En el sueño, así, así, cómo hace, así voy a preparar... con el sueño tiene que hablar. Así no más va a preparar... no, no; no va a hacer nada, entonces así, igual que trabajan en la Sagárnaga ${ }^{13}$. Entiende ¿no ve? En sueño pues, en sueño".

(La Paz: CADA/HISBOL, 1990), pp. 62-64. Forma parte de un proceso personal de iniciación. "Todos los lugares enseñan", considera Gregorio Condori, célebre "maestro" del sector de Faro Murillo, en El Alto de La Paz. Los "maestros" alardean de las visitas efectuadas a estos centros de "poder", lo que les acredita un prestigio "curricular" importante, a la vez que constituyen un testimonio irrefutable de sabiduría. Cerros, santuarios y apachitas (collados montañosos) son frecuentados en determinados períodos del año. Los "maestros" depositan sus taris de coca (tejido rectangular empleado tanto para el transporte de la hoja de coca, como en su lectura ceremonial), con la intención de que el lugar acreciente su perspicacia y ayude a "ver" con más claridad las claves interpretativas pertinentes en las consultas. Los lugares de especial relieve ceremonial en las inmediaciones de Achacachi, capital de la provincia de Omasuyos, se encuentran en Santiago de Ojje, Copacabana, Surucachi; los cerros de Jipi y Pachjiri, así como diversas apachitas en dirección a las serranías de Larecaja.

10 La investidura completa precisa de un ciclo de tres visitas a los centros de poder. El número "tres" aparece con frecuencia en la parafernalia ceremonial aymara, como recoge Hans VAN DEN BERG, Diccionario religioso aymara (Iquitos, 1985), p. 94, e incluso fundamenta la eficacia de un ciclo ritual completo.

11 La mesa es una ofrenda compleja constituida por ingredientes de naturaleza diversa (animales, minerales y vegetales) que satisfacen las expectativas culinarias de los diferentes comensales sagrados a los que se destinan. Gerardo FernándeZ, "Sullu, mesa y lógica social aymara", RDTP, XLVIII (1993), pp. 85-115. Sobre el origen etnohistórico de los ingredientes y su localización en diferentes preparados ceremoniales andinos, Louis GIRAULT, Rituales en las regiones andinas de Bolivia y Perü (La Paz, 1988), pp. 156-254.

12 Cualquier candidato o aspirante a "maestro" necesita solicitar previamente "permiso" en un lugar de especial significación sagrada para poder iniciar su formación. La falta de este requisito desacredita la labor ceremonial del implicado, resultando incluso potencialmente peligroso para su salud.

13 La calle Sagárnaga constituye uno de los contextos rituales más importantes de la ciudad de La Paz. En ella trabajan los "maestros" kallawayas procedentes de la Provincia Bautista Saavedra, al Norte del Departamento de La Paz, y ahora afincados 
G. F.-A usted cuando le van a preguntar algún problema en coca, así antes de saber ¿qué tiene que hacer?

M. CH.—En primer lugar, tiene que ir pues, por eso pues, al este el Ojje, Jipi iya? Entonces pagan; hay que pagar a los cerros, hay que pagar; el 'maestro', el 'maestro' tiene que pagar, él saca también pues. Él tiene que sacar pues permiso, jrecién no más! Para sacar, para preparar... ipara todo pues! recién, recién, recién; cliente está recién, cuando ya aprende, cuando ya sabe, recién va a captar pues. En el sueño, cuando ya va a captar, cuando ya va a explicar, cuando va a enseñar, cuando saca la suerte ya todo, jrecién no más! Algunos saben, los 'maestros' buenos 'maestros' ¡claro que sí! bueno explican; algunos no saben, algunos 'maestros', mentiras, imentiras no más! Aficionados no más, aficionado no más, claro que algunos no saben ipor plata no más! ${ }^{14}$ Yo no".

G. F.- ¿Cómo sabe ser buen "maestro"?

M. CH.—Experiencia, eso es pues. Eso es lo que estoy hablando ¿no ve? Claro que cuando vayamos a Ojje, cuando vayamos a aquel cerro de Jipi, cuando saquemos una licencia de él, en ahí explican los 'maestros'... así, así, todo, todo; qué cosa hablan para sacar, para mirar las cocas, para naipes ${ }^{15}$, oráculos, para preparar mesas... así, digamos, así indican ¡Como gente! Como estamos hablando así, igual no más hay que hablar, igual no más hablan los 'maestros'. Como este, como ahorita estamos hablando ¿no ve? Así vamos a charlar, así vamos a trabajar, así, igual no más. Tie-

como "residentes" en el entorno urbano paceño. En la Plaza de San Francisco atienden tanto yatiris como charlatanes, que hacen propaganda de sus preparados y remedios. Un poco más arriba se encuentra la calle Linares, donde se localiza el conocido "mercado de las brujas", repleto de puestos con especies vegetales propias de la farmacopea tradicional y elementos rituales para la elaboración de ofrendas. Buena parte de los yatiri y "maestros" que ocasionalmente aparecen por la ciudad contactan con las "caseras", vendedoras de remedios, para formalizar su cartera de clientes, con la correspondiente comisión. Sobre el mito etnográfico del kallawaya urbano ver, Pietro VUlPIANI, "Etnomedicina e sistema medico ufficiale in Bolivia. Il percorso storico di un gruppo di terapeuti itineranti delle Ande boliviane: I Kallawaya", Sociologia (1993), pp. 389-422.

14 El "maestro" preocupado en exceso por la "plata" y el enriquecimiento se encuentra bajo el control social que suscita la sospecha de ser layqa, "brujo".

15 La suerte predictiva de los naipes o baraja española, de indudable origen europeo, ha conseguido adaptar parte de su iconografía y contenido conceptual al contexto andino. La irrelevancia aparente de género entre "sotas", "caballos" y "reyes"; la vinculación del "oro" con la riqueza y la "plata", las "copas" con el trago, los "bastos" (espinos) con el "daño" (brujería) y las "espadas" con la justicia, atestigüan, junto al marco de referencia que posibilitan las figuras, una concepción plástica de los sucesos que preocupan al cliente. 
nen que hablar los 'maestros' con el achachila, con el santo, eso es pues. Recién, los achachilas, en el sueño se encuentran. En sueño pues, en ahí recién pues. Hay que hablar no más. Cuando así no más vas a preparar... no, no ¡falso es! Hay que hablar no más, pero en el sueño va a decir ¿no ve? En él usted, iqué bueno si es que ve!, si es que quiere aprender, hay que saber con todo $\mathrm{fe}^{16}$. Entonces es que ya cuando vas a pensar, cuando ya vas a cumplir estas mesas de inciensitos, sahumar... ¡todo! recién pues ya va a revelar. Seguramente este rato te va a waykiyar (engañar, confundir); claro que otra cosa, pero no es achachila, no es una sola, no es una sola ${ }^{17}$, otra cosa es lo santo; santo es otra cosa, los achachilas, otra cosa, los dicen que... los ñanqhas, saxras dicen que es ino ve? ese es 'maliño' (maligno) otra cosa. También las 'tiras' (tierras) ${ }^{18}$, otra cosa; también esto... las chullpas ${ }^{19}$ dicen que es awichas, chullpas... otra cosa.

16 La experiencia onírica constituye una puerta de acceso al conocimiento que sólo pueden franquear los que saben sonar y contemplar las imágenes pertinentes. Sobre la relevancia de los sueños en las sociedades indígenas americanas y sus variadas consideraciones en relación con la realidad, ver Bárbara TEDLOCK, "The culture of Dreaming among americanists", De palabra y obra en el Nuevo Mundo: Imágenes $y$ acciones interétnicas (Trujillo, 10-16/XII/1992). Mario POLIA y Fabiola CHÁvEZ, "Ministros menores del culto, shamanes y curanderos en las fuentes españolas de los $S$. XVI-XVII, Revista Anthropologica (1994), pp. 9-48, presentan un análisis comparativo de fuentes etnohistóricas en el que se aprecia el valor otorgado a los sueños, como fórmula específica de conocimiento predictivo, entre los especialistas rituales andinos, precisamente los responsables del culto popular, durante la Colonia.

17 Existe una variedad de entidades religiosas y personajes sagrados, a los que es preciso atender en el agasajo de las ofrendas ceremoniales. Gerardo FERNÁndEZ, "El banquete aymara: Aspectos simbólicos de las mesas rituales aymaras", Revista Andina (1994), pp. 155-189.

18 Ia pachamama es la "madre tierra". Sin embargo, posee diferentes denominaciones y advocaciones, no siempre propicias a los deseos humanos. Sobre la caracterización y atribuciones de la pachamama en los Andes, ver A. M. MARISCOTTI, Pachamama Santa Tierra. Contribución al estudio de la religión autóctona de los Andes centro meridionales (Berlín, 1978). Los vínculos establecidos entre la pachamama "madre tierra" y la Virgen María en los Andes son apuntados por Homer L. FIRESTONE, Pachamama en la cultura andina (La Paz, 1988).

19 Cbullpas, los gentiles, los que poblaron el altiplano en tiempos del ch'amak pacha (época oscura), antes del diluvio y que fueron muertos por el agua y el fuego solar. Se identifican con los restos arqueológicos y las tumbas antiguas. Algunas poblaciones aymara, próximas a los últimos enclaves uru-chipayas que sobreviven en las inmediaciones del lago Coipasa, denominan chullpas a los representantes de este grupo étnico. Sobre los caracteres del grupo uru-chipaya, Alberto GuERRA, Chipaya: Un enigmático grupo bumano ( $\mathrm{La} \mathrm{Paz}, 1991$ ), ha publicado una breve monografía etnográfica, así como Nathan WATCHEL, Le retour des ancêtres. Les uru XXe-XVIe siécles. Essai d'bistoire regréssive (Paris, 1991). 
También las qalas ${ }^{20}$, pedras (piedras), otra cosa; también 'aires' que dicen wintu (viento) ${ }^{21}$ ¿no ve?, otra cosa. También ¿qué se llama?... 'tío' ${ }^{22}$, claro tío, otra cosa. Ahora... ¿con qué va a hablar, a ver...? Esa es la cosa. Seguramente Gerardo, va a waykiyar (engañar), entonces ese es problema; entonces cuando usted vas a contactar con el saxra con el este... maliño (maligno) ¡brujo vas a ser! Seguramente ese es brujo; si usted vas a contactar con el pachamama, con el achachila, ya ese es 'espiritista' ${ }^{23}$,

20 El culto a las piedras y a los cerros es común en todo el área andina; ver Gabriel MARTíneZ, "Los dioses de los cerros en los Andes", Journal de la Société des Américanistes, 69, pp. 85-115. Piedras y cerros constituyen un modelo metafórico orgánico en relación con la estructura y funcionamiento del propio cuerpo humano; ver Joseph BASTIEN, "Etnofisiología andina. Evidencia lingüística, metafórica, etiológica y etnofarmacológica para conceptos andinos sobre el cuerpo", Arinsana, 1 (1986), pp. 5-24, en relación con el modelo de "cuerpo montaña" localizado en ciertas comunidades kallawaya. En otra parte: Gerardo FERNÁNDEZ, "Etiología, terapia e identidad: Las mesas aymara", Revista de Antropología Americana, 25 (1995), he considerado la relación establecida entre "cuerpo" y "piedra", por parte de los aymara. El hermetismo de la roca, su carácter duro y "cerrado" son considerados pertinentes en la valoración de los cuerpos sanos y resistentes a la enfermedad, por parte de los yatiri.

21 Los malos "aires" y efluvios malignos son causa de enfermedades en diversos sectores de los Andes. Así lo señalan las informaciones de David FrisANCHO, Medicina indígena y popular (Lima, 1986) en el área de Puno; Federico AGUILÓ, Enfermedad y salud según la concepción aymaro-quechua (Sucre, 1985) en las poblaciones potosinas; Héctor Omero PALMA, La medicina popular en el Noroeste argentino (Buenos Aires, 1978) provincias de Jujuy, Salta y Tucumán; Mario PoliA, Las lagunas de los encantos. Medicina tradicional andina del Perú Septentrional (Piura, 1988) en las alturas de Huancabamba, próximas a la frontera peruana-ecuatoriana; Jorge A. LIRA, Medicina andina. Farmacopea y ritual (Cusco, 1985) en las serranías cuzqueñas; o Carmen MUÑoz BERNARD, Enfermedad, daño e ideología. Antropología médica de los Renacientes de Pindilig (Quito, 1986) en Ecuador.

22 "Tío" es el saludo estipulado, en el área rural, que la persona más joven debe dedicar a la de edad superior al cruzarse, sean o no vecinos de la misma localidad. El término "tío", sin embargo, se aplica al "demonio", patrono de las minas y socavones del altiplano; dueño del mineral a quien se rinde culto, particularmente cada primero de agosto, con la intención de que no esconda las vetas y las ofrezca con generosidad.

23 Término aplicado a los ch'amakani, especialistas rituales de la máxima jerarquía, que se caracterizan por su facultad de hablar en la oscuridad con los "espíritus" y entidades anímicas (ajayus, animus), tanto de los pacientes como de los inculpados en los hechos que ocasionan la consulta. Conversan directamente con los seres tutelares que les apoyan, incorporando diversas voces con timbres diferentes, según el carácter de los personajes convocados. La sesión se realiza siempre en un recinto oscuro, donde el ch'amakani ("dueño de la oscuridad") convoca y conversa con los diferentes personajes implicados. Los propios tutores ceremoniales, en las voces que el ch'amakani reproduce, increpan a los "sospechosos" de causar el daño que aflige a los dolientes. 
claro que vas a invitar las tiras (tierras), los achachilas, para trabajo, para todo, para viaje, para curar, eso es pues. Solamente, claro que vas a contactar con el 'tío', maliños, con el diablo ¡ha! seguramente, ¡brujo es pues!, brujo es, pero no cura nada, nada. Cuando vas a querer curar, no ve, seguramente va a presentar ${ }^{24}$, una persona muy enfermito, bien encarnadito, vas a presentar... entonces vas a ser 'fresco', yatiri fresco (novato), entonces, 'yo voy a curar, yo sé todo', diciendo, iya!, cuando lo vas a curar, ese ratito mismo va a morir, es el fin. 'Ya ¡carajo!' a usted van a caer a tranco ¿Ya ve?.

G.F.-¿Cómo sabe uno si tiene que trabajar con las pachamamas, si tiene que trabajar con los achachilas...?

M. CH.- "Por eso pues hay que ir; por eso hay que ir, por eso hay que ir al Jipi, al Ojje, jrecién pues! Hay que explicar no más, pero yatiri tienes que explicar. Algunos, pero saben; algunos también, no saben, no saben. Distinto es pues en sueño, pero yatiri, no es igual. Algunos yatiri otra cosa hablan, algunos yatiri, otra cosa hablan, algunos yatiri, otra cosa hablan, otra cosa, otra cosa, otra cosa... ¡No es igual! No, los yatiri, ¡no! no es yatiri, ipuro aficionado no más es! ${ }^{25}$ Así no más, ipeligroso es! Cuando va a chocar con el enfermo... ya va a presentar... no, no va a curar. Tengo mi amigo en Achukalla en todas partes de los yungas, en aquí mismo también hay. Cuando yo curo... ya sana pues. Una noche no más yo curo. No, no yo no curo nada, ni dos noches ni tres noches nada. Cuando yo curar ya comienzo a las ocho de la noche y hasta doce, hasta la una. Después, los enfermos, los que están mal las gentes, cuando yo curo, tienen que dormir, una horita, dos horitas y cuando levantan, ya yo pregunto: ‘Cómo estás señora? ¿Estás sana? ¿Estás bien? ¿Estás malsita? Si, ¿estás mal?'. Ya, 'estoy sana'. Yo leo ${ }^{26}$. ¡Ya!, sanó. Los médicos no hacen nada. No, imédicos nada! Seguramente los médicos ya no curan nada, pero claro que sí, algunos con sus 'corpos' (cuerpos) claro que seguramente

24 El yatiri tiene la obligación de "presentar" al doliente ante los seres tutelares que van a intervenir en su cura; para ello emplea los recursos propios de la parafernalia ceremonial aymara, así como las fórmulas pertinentes en el trato y conversación habituales ante personas de autoridad y prestigio.

25 La necesidad económica y la posibilidad de arañar unos pesos ejerciendo como yatiri provocan un alto grado de intrusismo" en el mercado ceremonial paceño. Los "maestros" ya establecidos en los sindicatos de yatiris de El Alto de La Paz se quejan de la afluencia importante de campesinos que, apenas con ciertas nociones sobre la predicción de la hoja, ejercen como "maestros", imponiendo una férrea competencia por la consecución de una cartera estable de clientes.

26 Es preciso confirmar la etiología de la enfermedad y la eficacia de la terapia empleada mediante una consulta postrera a la hoja de coca. 
malogrados, ese cura ya, los malogrados, ese no más curan los médicos ${ }^{27}$. Solo que de saxras, saxras se llaman los maliños, saxra, ñanqba, pero usted sabe ¿no ve? Esas clases, saxra, diablo ¡claro! algunos dicen Satanás; de saxra siempre agarran sus ajaynu, sus animus, su espíritu siempre ${ }^{28}$. Eso no más, pero cuando los saxras entran los cuerpos, aquí, el corazón, el corazón entra ya, todas, todas partes le entra ${ }^{29}$. Cuando algunos yatiris, cuando cuando también... iigual, pero no saben captar nada! Para sí están curando, están frotando todas partes ${ }^{30} \ldots$ iya! No, no sana, no sana, así es".

G. F._¿Cuántos tipos de mesas trabaja usted?

M. CH.—-Según es pues, según. No es igual, no es igual, don Gerardo; mesas claro que, pero mesas, claro que algunos, alguna gente quieren para viaje, para negocio, para trabajo, para todo. Algunos quieren hartas mesas, no una mesa.

G.F.- ¿A quién se hace esa "pagancia"? ${ }^{31}$

M. CH.- A la tira no más; pachamama siempre. Ya que usted quiere saber, por esta razón hay que sacarnos un 'permiso'. Él no más va a explicar, él no más va a hablar, en el sueño no más. Recién no más va a cum-

27 Los médicos muestran su eficacia en el tratamiento del "cuerpo", no así respecto a las aflicciones que habitualmente afectan al alma de las personas, a través de las diversas entidades que la conforman. Los "maestros" diferencian las enfermedades "de la gente" (aquellas que son competencia del yatiri y que normalmente tienen que ver con las aflicciones del alma), de aquellas otras propias del "médico" o del doctor, institucionalizadas en los términos más agresivos de la terapia clínica occidental: vacuna, inyección, suero o "transfusión"; por no citar al terrible "operador", personaje mítico, conocido en aymara como kharisiri, cuya destreza consiste en la extracción de líquidos vitales, la grasa y la sangre de sus víctimas, con ánimo de lucro.

28 El "alma" de los seres humanos está constituida por diferentes entidades (ajayu, kuraji, animu), susceptibles de sufrir acontecimientos o sucesos que afectan la salud de las personas. Estas parcelas o entidades anímicas son apresadas y retenidas («tapiadasn) por los seres maléficos del altiplano, que las "devoran" paulatinamente agudizando el cuadro clínico del doliente afectado.

29 Las enfermedades del "alma" no son accesibles a la medicina científica. El corazón constituye el "centro" anatómico del ser humano. El valor otorgado al "centro", taypi, en las diversas concepciones espaciales (ver Gilles RIVIERE, Sabaya: structures socio-économiques et représentations symboliques dans les Carangas, Bolivie, Paris: Ecole des Hautes Etudes en Sciences Sociales, 1982), religiosas y sociales aymara, le atribuye un poder aglutinante y estabilizador. La pérdida de dicho "centro" supone una seria amenaza, tanto para el orden comunitario como para la salud del individuo.

30 Los procedimientos de higiene simbólica o "limpia" son frecuentes en la terapia aymara. Las "limpias" ceremoniales pretenden, a través de los frotamientos, eliminar la contaminación que produce la enfermedad; así se consigue alejar el "daño", la desgracia, la pena, el infortunio o la envidia que ocasionan la aflicción del doliente.

31 "Pagancia", ofrenda. 


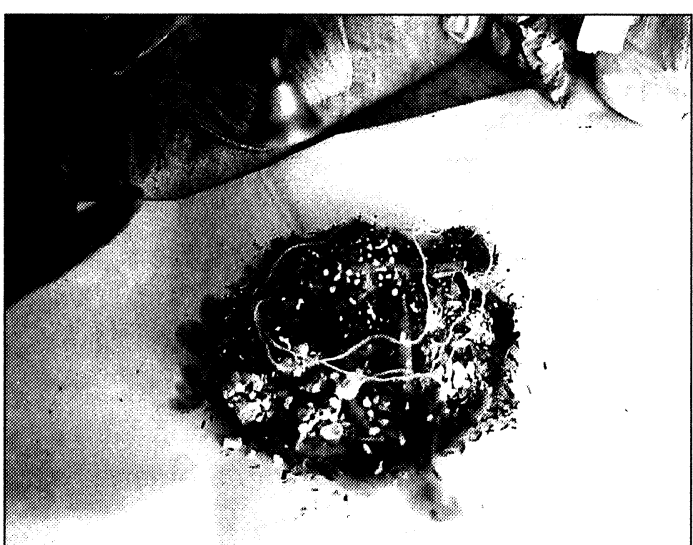

FIG. 1.-Ofrenda para kunturmamani; el hogar campesino plir, recién vas a captar todo. Cuando así no más te vas a aprender... no, no ¡no! No hace nada. Yo trabajo viaje, para trabajar, 'pa' negocio; algunos quieren para almacenes, garajes, ferreterías, para eso yo trabajo mesa no más ${ }^{32}$. Tulsi misa ${ }^{33}$ es pues, tulsi misa, llamp'usitus ${ }^{34}$. Siempre pues llamp'u, sebo de llama ¿no ve? Sebo de llama claro que, con eso no más. Pues llamp'u, tulsi misa, wira q'uwa ${ }^{35}$, pero...

no es igual. Con lo que yo trabajo, así mismo no más, pues ¡eso no más! con mesa no más, pues misa untu, wira q'uwa... jeso no más!’.

G. F.- ¿Cómo coloca?

M. CH. -Parte por parte pues ${ }^{36}$. Parte por parte, para que se recupere (el enfermo). Eso pregunto, pero ¿para cómo te quieres saber eso? Eso

32 La mesa adapta sus características configurativas a las necesidades del entorno urbano. La conceptualización tecnológica aymara se fundamenta en dos principios básicos: por una parte, el conocimiento basado en la experimentación empírica, por otra, el ejercicio del principio de reciprocidad que liga a las personas con los seres que ejercen una celosa tutela sobre los humanos y la satisfacción de sus necesidades. Jan V. KESSEL, "Tecnología aymara: Un enfoque cultural", Hans VAN DEN BERG y Norbert SCHIFFERS, La cosmovisión aymara (La Paz, 1993), pp. 205-210. La rentabilidad de los negocios y la presencia de clientes se procuran de forma ceremonial con el sacrificio culinario de la mesa durante la primera quincena de agosto, ofrecida generalmente a la pachamama.

33 Tulsi misa, ofrenda dulce. Está constituida por una serie de figuras azucaradas, caramelos y frutas pasas ( $k$ 'isa), con diferentes motivos iconográficos alusivos al talante de la ofrenda.

34 Llamp'u. Grasa procedente del pecho de la llama, de su "centro". El término llamp'u se aplica a las sustancias suaves, "molidas". Ludovico BERTONIO, en su Vocabulario de la lengua aymara (1612) (La Paz, 1984), tomo II, p. 201, sitúa el término llamp'u dentro de un campo semántico que alude a las recomendaciones morales que deben imperar en las relaciones humanas.

35 Wira q'uwa, especie herbácea de altura, empleada como ingrediente habitual en las ofrendas ceremoniales a la tierra.

36 Es preciso convidar a cada comensal "parte por parte", es decir de forma diferenciada. 

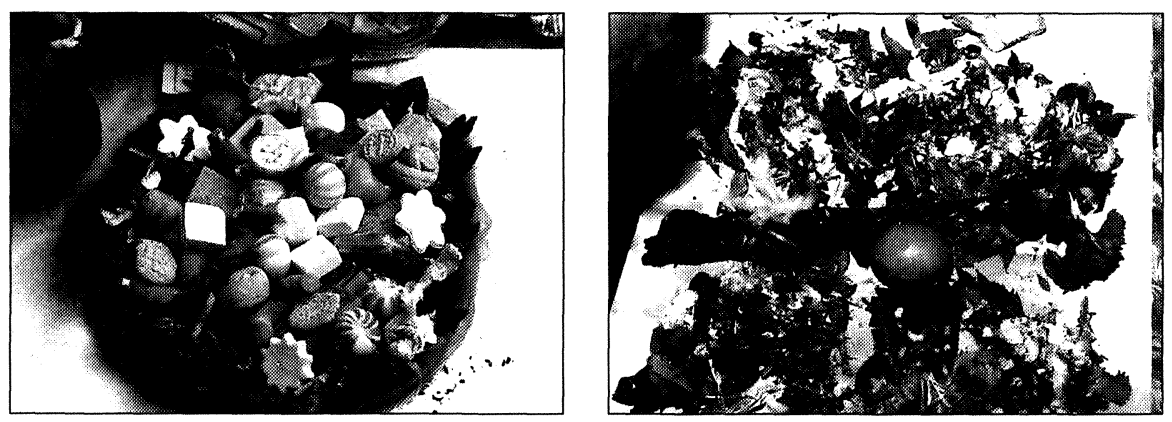

FIG. 2.a y b.-Ofrendas para pachamama, la "madre tierra".

quiero preguntar. De repente, seguramente yo te voy a explicar, ¿no ve?, cuando ya sabes ¿no ve? ahora te voy a decir así yo trabajo, así, así, así; de repente usted puedes trabajar ¿no ve ${ }^{37}$ Usted mismo, seguramente puedes caer entonces, cuando vas a hacer las mesas, las tiras seguramente va a amarrar jtodo! (sonríe). Trabajo siempre con mesa, tulsi misa, claro que trabajo wira q'uwa jeso no más, igual no más es! Janiw impurtantkiti kulukañaj. ¡No es importante colocar! ${ }^{38}$. Seguramente bueno, hay que captar no más. Hay que hablar no más con el achachila. Usted, cuando vas a saber, cuando vas a contactar con el achachila, usted preparas no más, como sea ${ }^{39}$. Como sea recibe, no más. La pachamama, todos reciben no más. No es, no es... ¡distinto no más! No importa preparar, algunos claro que sí, ponen claro que este llamita hacen del sebo del llamp'u, hacen llamita, luego ponen el centro. Después ya con lana colora (lana de color), después wira q'uwa ¡bueno! primero papel blanco; sobre eso lana color, sobre eso wira q'uwa o llamp'u, luego. Algunos hacen una

37 Ejercer como "maestro" sin pasar previamente por el proceso de iniciación, que fundamenta la solicitud de "licencia" y la consiguiente investidura de "poder", resulta no sólo peligroso, por la actuación de los personajes tutelares implicados, sino fraudulento. Se achaca habitualmente a los "maestros" urbanos, especialmente preocupados por los rendimientos económicos, este tipo de carencias en su formación.

38 Manuel Chura, en contraste con otros numerosos especialistas rituales que sí otorgan una importancia al orden configurativo de la ofrenda, antepone la conversación y el contacto con los comensales sagrados frente a las posibilidades estéticas de la mesa. Desconozco hasta qué punto incide en esta consideración su ceguera y la probable dificultad en preparar "lindas" ofrendas, calificativo habitual entre los "maestros" ceremoniales para resaltar el valor culinario sensible de la mesa. Manuel Chura testimonia en su relato el privilegio concedido a la ética frente a la estética ceremonial.

39 Cada yatiri prepara las ofrendas de una forma diferente. Lo importante es que el resultado de la elaboración sea satisfactorio. 
cajonita ${ }^{40}$ algunos hacen así, redondito en papel, papel blanco, algunos hacen periódico, algunos hacen con papel verde, con papel blanco, ¿así, no? Claro que así es pues... claro que algunos... ino! no es importante. Depende de usted. Usted puedes hacer no más. Trabajo igual no más es, igual no más es; sólo que tienen que recibir las pachamamas. Tienen que recibir, tiene que ayudar pues al trabajo, 'pa' todo. Eso es lo importante".

G. F.- ¿Cómo hay que hacer para que reciban bien las pachamamas?

M. CH.—Por eso es pues; por eso hay que contactar pues. Pachamamas reciben cuando va a conocer va a recibir, cuando no va a conocer ino pues! En balde te vas a preparar parte por parte jen balde! te vas a preparar pues. Aun cuando se preparan ibuen adornito! siquiera adorno, no va a recibir, las pachamamas, no va a recibir porque no conoce ¿no ve? No conoce. A ver, digamos, digamos, una persona, una persona; seguramente usted vas a conocer una persona ¿no ve? un caballero digamos. Una caballera, seguramente no va a conocer, no vas a charlar con ella ¿no ve? Claro que sí; no va a recibir pues. Seguramente vas a charlar con ella, claro que al charlar con ella, hablamos con el caballero. Ya jamigo vas a ser! ¿no? Claro que sí; ahora, ese caballero, seguramente... '¿cómo está?'. Va a recibir pues, va a recibir, como sea siquiera. Si es que no va a conocer...no, no recibe. En balde vas a hacer cuando sea bien adornadito, siquiera así, parte por parte, ahora cruz ${ }^{41}$, ahora con sullitos ${ }^{42}$, todo... ino, no, no va a recibir! No, no. En balde te vas a gastar pues. Siempre primero tienes que conocer pues. Hay que hablar no más con el este...en primer lugar, con el santo, después ya con el achachila. Ir no más. Ya conoce... irecién!, recién, recién. De por sí ya vas a aprender todo, de por sí. Depende de usted.

G. F.- ¿Usted así ha aprendido, hablando con los santos, con el achachila?

M. CH.- "Todo yo hablo. Cuando yo curo, yo estoy preparando una mesita, no más preparo para curar, presento con llamp'usitus, llamp'u, eso no más se prepara, grasa no más ${ }^{43}$; otra cosa yo preparo, no es mesa.

40 Caja, plato; envoltorio de la ofrenda.

${ }^{41}$ La distribución de los ingredientes en la ofrenda adopta, frecuentemente, una disposición cruciforme sobre el espacio de la mesa.

42 Sullu, feto. Ingrediente de especial relevancia y prestigio en las diversas ofrendas ceremoniales. Se emplean preferentemente fetos de llama, los de mayor significación y estatus simbólico, en el caso de las ofrendas a la pachamama. Los fetos de chancho (cerdo) y oveja aparecen en las ofrendas dedicadas a los chullpas, los «antiguos". Cfr. Gerardo FERNÁNDEZ, art. cit, 1993, pp. 104-115.

43 La grasa de llama es una especia ceremonial muy apreciada en el área andina. El "Sebo" es el reservorio energético vital cuya presencia en las ofrendas refleja una importante carga simbólica respecto a los fluidos corporales. Así lo atestigua el traba- 


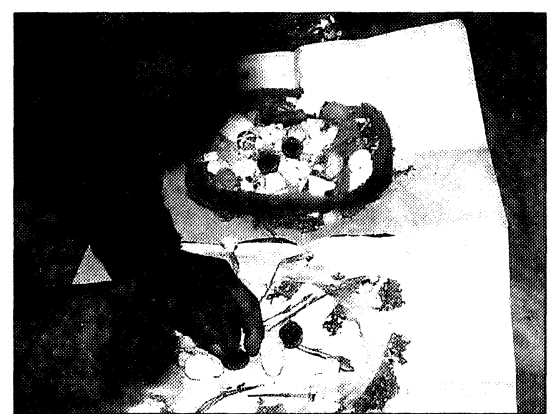

FIG. 3.-Ofrenda compleja, constituida por dos platos destinados a "gloria"

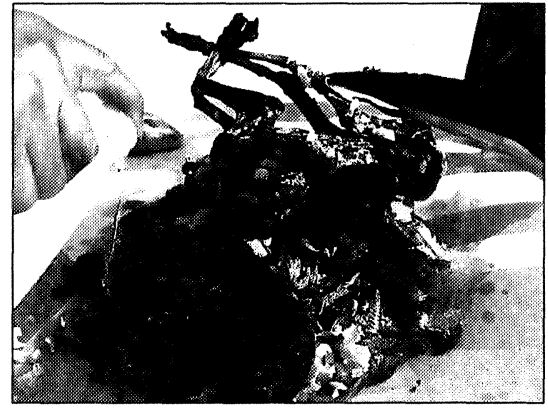

FIG. 4.-Chullpa mesa.

Yo trabajo con el llamp'u no más para curar; para curar, con el llamp'u no más. Con llamp'u preparo bultitos no más. Bultitos no más preparo. Yo pongo ahisito al corazoncito, ahisito yo pongo por unas medias horas, una horita, así. Recién ya bajo ${ }^{44}$, ya después algunos llevan, después ya recién pues ya sana la gente, sana; con llamp'u, así no más".

G.F.- ¿No siempre es necesario preparar mesa para curar?

M. CH.—No, no, no, no. ¡Distinto es! Para invitar la pachamama no más la tulsi misa, tulsi. Después claro, para curar, otra clase es. Otra clase. Después también para... ¡no es igual pues! No es igual. Algunos claro que enferman con el rayo, algunos ya enferman de tira, algunos claro que enferman después de este maliño, algunos claro chullpas, algunos... ¡no es igual!, pero ese chullpas, otra clase son sus comidas; rayos, otra clases; claro que este pachamamas otra clases, también los... ino es igual D. Gerardo! ${ }^{45}$ Ahora, ¡no puedes aprender! Ahora de un rato. Si es que quieres 'saber', primer lugar entonces tienes que ir no más al Ojje, Jipi. Recién ya vas a aprender ¡todo! Yo conozco todo. Si es que quieres hacer, entonces hay que ir, sa-

jo etimológico de Jan SZEMINSKI, Un curaca, un dios y una bistoria (San Salvador de Jujuy, 1987), p. 17, en relación con la crónica de Juan de Santa Cruz Pachacuti. Por otra parte, el sebo es la materia que permite reemplazar al animal (la llama) en el sacrificio de la mesa: "en su lugar ponemos pues llamp'un. Según la crónica del P. José DE ARRIAGA, op. cit., pp. 210-211, durante la Colonia la grasa de llama formaba parte de los ingredientes requeridos en la hechicería nativa para la reconstrucción iconográfica de cuerpos de personas aborígenes. Constituía la imagen o "doble" de la víctima a la que se pretendía ocasionar algún daño.

44 "Bajar", retirar. Implica cierto principio de verticalidad en la cura; es utilizado como sinónimo de "sanar".

45 Diversidad etiológica. Cada entidad implicada en la causación de enfermedades es satisfecha culinariamente de una forma específica; cada comensal tiene unas preferencias culinarias que es preciso atender de forma diferenciada. 
ber no más en primer lugar, todo, todo, todo. Hay que ir al Jipi, tienes que llevar. Hay que saber cómo está tu suerte (leer la coca)... no, pero. Hay que saber, pero; tal vez sea que tienes suerte para preparar... tal vez, no tienes. Hay que mirar, hay que saber no más. Ahorita, digamos yo te voy a decir, ¿no ve? así, así, así vas a preparar, así no más, así no más... ¡no! Primer lugar hay que saber no más; sacamos la suerte. A ver cómo, cual lado nos va a tocar ${ }^{46}$, cuantos días, según ${ }^{47}$. No es así no más, pero hay que saber no más... recién. Cuando yo quería saber, ¿no ve?, antes... ino me han dicho nada los 'maestros'! Mi 'maestro' no me ha dicho nada siempre; no me ha dicho nada, así no más. No me ha dicho nada; entonces cuando yo sé entonces, poco a poco, recién me ha explicado. Así, igualito hay que sacar no más... ¡recién! Hay que proceder, él va a decir; el 'maestro', el 'maestro' va a decir pues. Hay que conseguir un 'maestro', él va a decir, para qué va a decir. Él va sacando licencia; él va a explicar, él va a enseñar eso todo; él va a decir, recién ya usted puede preparar no más".

G. F.-Pero el "maestro" nunca explica cómo se coloca el llamp'u, como se coloca...

M. CH.—No, no; cuando tú vas a aprender, recién no más va a explicar el 'maestro' ${ }^{48}$, recién va a enseñar, así vas a preparar, así vas a preparar. Claro que seguramente yo te voy a decir, así vas a preparar, así vas a preparar... ¡recién! Yo también voy a sacar suerte... ya ¿cómo está? ¿Sabes o no sabes? Si es que ya, puedes preparar o no... ya, entonces... recién, recién. Ahorita te voy a decir, así no más, así no más... jno! Seguramente a mí me puede castigar el achachila; si, así es Gerardo. Hay que sacar no más; hay que sacar licencia, permiso. Algunos no conocen, de repente, algunas veces... layqa, puro layqa (brujo). No dicen nada. La gente que está maldecida, dicen. Yo no manejo. Para trabajar no más hay que saber. Los de este 'Corazón de Jesús' ${ }^{49}$, no preparan... jcuánto cobran!,

46 Es preciso ver qué "lado", "camino" o especialidad se ajusta mejor a las características del candidato. Depende de la especificidad de la competencia en el servicio que le corresponda ejercer al "maestro", según su selección.

47 El proceso de iniciación de un "maestro" ceremonial aymara requiere períodos cíclicos de adiestramiento que es preciso cubrir.

$48 \mathrm{El}$ aprendizaje es un reto personal individualizado y, frecuentemente, empresa que el "maestro" acomete "en solitarion. La eficacia de sus conocimientos y la versatilidad de su sabiduría son deudoras, en gran parte, de las imágenes oníricas y de las conversaciones que el candidato establece con los achachilas y otras entidades de poder.

49 Santuario de yatiris y "maestros" en su mayor parte emigrantes, que proceden de comunidades aymaras próximas a $\mathrm{La} \mathrm{Paz}$, destacando una notable presencia de "maestros" originarios de las proximidades del Lago Titicaca, que se localiza en las alturas de La Ceja, en el Alto de La Paz. 
paquetitos, no ve; no vale para nada. Bueno sí, en Corazón de Jesús tienen gente harto, ¿no ve?, pero seguramente, no saben nada, engañan. Por eso te digo, ¿no ve?, en primer lugar, los 'maestros' tienen que saber don Gerardo. Hay que sacar licencia pues... recién. Hay que saber no más. Si es que no vas a empezar, ¡no pues! no va a revelar nada; no hablan los achachilas nada. Hay que contactar pues".

Merece la pena resaltar varios aspectos del testimonio aportado por Manuel Chura. Especialmente el capítulo destinado a la experiencia onírica, la contemplación de imágenes y la conversación pertinente con los seres tutelares aymara.

El sueño de iniciación es una de las vías de mayor consideración y prestigio en el proceso de formación de un "maestro" ceremonial aymara. La capacidad de contemplar imágenes, lo suficientemente aleccionadoras, sobre las técnicas usuales empleadas por los "maestros" en el desempeño de sus capacidades predictivas, terapeúticas o ceremoniales, que son "reveladas" por los seres tutelares durante el sueño, supone una vía de acceso al conocimiento especializado del yatiri, prestigiosa y de gran relevancia. La incapacidad manifiesta para recibir este tipo de información onírica limita la eficacia ceremonial de cualquier posible candidato. La experiencia onírica y su contenido "docente" es contrastada con un intenso período crítico, por parte del iniciado, quien reflexiona sobre los hechos "vistos" en el sueño y la información contenida, tanto en las imágenes contempladas, como en las palabras y conversaciones sostenidas con los diversos actantes de las diferentes escenas compositivas del sueño.

Así, Carmelo Condori Calsina, maestro de prestigio en la comunidad de Toque Ajllata Alta, paisano por tanto de Manuel Chura, recuerda con interés su propio sueño de iniciación, describiendo con todo lujo de detalles los "lugares" visitados en el sueño, particularmente "cerros", así como las diversas pruebas a las que se ve sometido en su proceso de formación, por parte de otros actantes especializados. Estos "ayudantes", que van resolviendo las trabas que a Carmelo Condori se le presentan durante su aprendizaje, son especialmente "clérigos" y gente de "iglesia". Las estrategias predictivas de la lectura de la coca, las variedades de ofrendas, mesas, y su sacrificio correcto; la diferenciación de los ingredientes, la precisión del uso estipulado de las manos en cada caso, el valor de las libaciones ceremoniales (ch'allas), etc. Todo este cúmulo de recursos ceremoniales que el candidato debe conocer y utilizar con maestría y conocimiento, responde a las escenas contempladas en el sueño, así como a las conversaciones y palabras propuestas como fórmulas de interpelación reflexiva. La supuesta 
capacidad del "maestro" es contrastada en pruebas sucesivas, enmarcadas en las diferentes escenas oníricas que el candidato supera, merced a los primeros fracasos, que en cualquier caso suscitan su crítica y reflexión personal posterior, ya desde el estado de consciencia. Si la vivencia onírica resulta fundamental en la contemplación figurada de "imágenes" que consolidan el especializado conocimiento del yatiri, la conversación y el uso adecuado de la "palabra", no le van a la zaga ${ }^{50}$. "Hay que hablar pues", insiste repetidas veces Manuel Chura respecto a la ética que para un avezado "maestro", como es su caso, implica la solicitud de "permiso", la presentación de dones y los ruegos que cualquier aspirante a "maestro" debe realizar en lugares de especial caracterización sagrada. Es preciso identificar con precisión las palabras del achachila, comprobar, mediante la lectura de hojas de coca, su decisión final; es decir, localizar el "camino" profesional y de servicio para el cual el aspirante ha sido elegido.

El candidato, una vez que ha solicitado el "permiso" y resulta seleccionado en una determinada especialidad ceremonial, tiene que conversar en sueños con los personajes que, a partir de ese momento, serán sus principales avalistas y tutores sagrados en los procedimientos rituales que emplee. Tiene que conocer sus preferencias culinarias y atender las formalidades rituales de acuerdo con sus gustos, "caprichos". El éxito de su competencia como "maestro" depende de su capacidad conversadora. Ha de rogar con infinita paciencia y sin brusquedades, tal y como recomienda la ética formal aymara. Con el tiempo se convertirá, por una parte, en un avezado anfitrión en los convites y ofrendas de sacrificio que precise convocar ritualmente para la resolución de cualquier asunto; por otro lado, la frecuencia y el hábito en el uso de la palabra, respecto a sus tutores ceremoniales, le convertirán en especializado "conversador", eficaz en el planteamiento de las aflicciones sufridas por los clientes que acudan a consultarle.

La tipificación explícita de cada caso aconseja, en función de la naturaleza del mal, la competencia de un determinado "maestro". Ignacio Caillanti, "maestro" originario de la misma localidad altiplánica a la que pertenece Manuel Chura es más competente que Carmelo o el propio

so Modesto Capcha, yatiri "residente" en el sector de Faro Murillo, en el Alto de La Paz, duda seriamente de la posibilidad de que un gringo (extranjero) pueda ejercer como yatiri, no tanto por la aparente dificultad de configurar las ofrendas correctamente, sino por el uso inadecuado de las "palabras" en el proceso ritual de elaboración de las mesas. El ruego y la presentación de los pacientes, el planteamiento del problema y el agasajo de dones a los seres tutelares aymara, exigen un adiestramiento básico, relativo a las maneras de conversación, semejante al que se produce en las asambleas comunitarias, donde las intervenciones presentan unas formas estereotipadas que han de respetarse, criticándose a los que no saben cumplirlas satisfactoriamente. 
Manuel en los asuntos que tienen que ver con "gloria" o con el rayo ${ }^{51}$. La "marca" estrellada que luce en su mano derecha atestigua la selección de que ha sido objeto por parte del rayo y, por tanto, en cualquier asunto que tenga que ver con esta entidad es preciso acudir a Ignacio porque "recibe" mejor las ofrendas y el "maestro" conoce al detalle los hábitos culinarios y el tratamiento de la conversación que resultan más pertinentes. La comunidad lo sabe y elige a cada "maestro" en función de los caracteres propios de cada consulta. En realidad, los mismos "maestros" recomiendan a sus pacientes acudir a uno u otro especialista en razón de la tipología del caso y la competencia específica de cada uno. La hoja de coca decide finalmente con qué "maestro" la ofrenda va a ser mejor recibida.

El uso habitual de la conversación y el placer que procura entre los aymara, se traslada a sus relaciones con los seres tutelares sagrados. Las formas de conducta consideradas pertinentes por la cortesía aymara se utilizan igualmente en el campo ceremonial; así lo señala Hans van den Berg en su minucioso trabajo sobre los rituales agrícolas aymara ${ }^{52}$, o el propio Domingo Llanque ${ }^{53}$. El contacto que el especialista ritual mantiene constantemente con los seres tutelares consolida una relación estrecha que Manuel Chura esgrime como única garantía de éxito en las competencias del "maestro". Las imágenes oníricas y el empleo de la conversación sustentan las bases para una relación de cierta confianza entre el "maestro" y su tutor ceremonial, circunstancia que justifica la capacidad solícita del "maestro" cuando ha de pedir la intervención de su protector en la resolución cualificada de cualquier asunto que afecte a sus pacientes.

Imágenes, figuras y palabras constituyen parte esencial de los procedimientos ceremoniales empleados por el "maestro" y constituyen, asimismo, el objeto prioritario de su adiestramiento. Son las imágenes y las palabras las que permiten al "maestro" conversar sobre el "mundo" y sus conflictos con los únicos seres que, según las creencias religiosas aymara, están en condiciones de procurar bienestar y satisfacción a sus demandas.

\section{GERARDO FERNÁNDEZ JUÁREZ \\ Centro Superior de Humanidades Universidad de Castilla-La Mancha Toledo}

51 La parte de la "glorian incluye a toda una serie de entidades, personajes y objetos: santos, vírgenes, calvario, estrella, rayo, luna, sol, etc.

52 La tierra no da así no más. Los ritos agrícolas en la religión de los aymaracristianos (Amsterdam: CEDLA, 1989).

53 La cultura aymara: Desestructuración o afirmación de la identidad (Lima: TAREA/IDEA, 1990), pp. 41-99. 
El testimonio de Manuel Chura, especialista ritual aymara (yatiri) que trabaja a tiempo completo atendiendo a su clientela en la ciudad de La Paz, refleja la importancia de la conversación, el uso apropiado de la palabra, y la contemplación de las imágenes que los sueños iniciáticos procuran, en el proceso de formación de un "maestro" ceremonial.

Manuel Chura's document, an Aymara ritualist (yatiri) who works by taking care of his patients in La Paz, shows the importance of the conversation, the appropiated use of word and the sight of dreamed images during his initiation. 